\title{
Bárbara, una posible donante de órganos*
}

\author{
Drs. JUAN PABLO BECA I. ${ }^{1}$, MILA RAZMILIC T. ${ }^{2}$, MONTSERRAT RIUS A. ${ }^{3}$
}

1 Centro de Bioética, Facultad de Medicina Clínica Alemana - Universidad del Desarrollo.

2 Estudiante de Medicina, Facultad de Medicina Clínica Alemana - Universidad del Desarrollo.

3 Enfermera coordinadora de trasplantes, Clínica Alemana de Santiago. Santiago, Chile.

\begin{abstract}
\section{Barbara, a potential organ donnor}

This article presents the case of a 47 year old woman, on encephalic death state, who had not expressed her willing or acceptance for organ donation. The case is described as a narrative, contextualized, and in an anonymous way. A bioethical analysis of the family decision making and of the role of transplant coordinator is proposed. This presentation, with the description of its whole context and of the factors that influenced decisions, has the purpose to contribute to the development of deliberation competencies and to increase the awareness of the ethics problems of family decisions, of the conditions of anonymous organ assignation and of the of the end of life's meanings.
\end{abstract} of life.

Key words: Organ transplantation, organ procurement, transplantation conditioning, brain death, value

\section{Resumen}

Se presenta el caso de una mujer de 47 años, en muerte encefálica y sin expresiones previas sobre su voluntad de ser donante de órganos. El caso se expone como una narración contextualizada, anonimizada y seguida de un análisis bioético de las decisiones familiares y del rol del coordinador de trasplantes. La presentación, con una descripción del contexto y de los factores que condicionan las decisiones, tiene el propósito de contribuir al desarrollo de la capacidad deliberativa y a tomar mayor conciencia del problema ético de las decisiones familiares, del anonimato de la asignación de órganos y del sentido del final de la vida.

Palabras clave: Trasplante de órganos, donación de órganos, asignación de órganos, condiciones de la donación, muerte encefálica, sentido del final de la vida.

\section{Narración}

Tomás por favor contesta, por favor -pensaba Camila, mientras con cada repetición del tono de espera del teléfono se sumaba un poco de angustia.
Por favor, por favor -murmuraba como un mantra -por favor por favor-. Entonces del otro lado la voz adormilada de Tomás contestó: -Qué pasa Camila, son las 2 de la mañana...no estoy para tus leseras.

Mordiéndose la lengua respiró profundo.

*Recibido el 22 de enero de 2011 y aceptado para publicación el 12 de marzo de 2011.

Correspondencia: Juan Pablo Beca I.

Vitacura 5951, Santiago, Chile.

jpbeca@udd.cl 
- Tomás cállate, ¡se llevaron a la mamá a la clínica!

- ¿Qué le pasó? contestó al tiempo que estaba fuera de la cama, con esa rapidez tan característica de la urgencia, con esa mecanización tan propia del miedo.

- No sé, que importa eso ahora... nos vemos allá. Me llevo a Pablo también, está muy choqueado... él encontró a la mamá en el suelo.

- Ya ya, un beso... voy para allá!

La puerta del ascensor se abrió al lobby del quinto piso y de golpe salió un hombre de unos 24 años, Tomás, con su cara alargada, pómulos marcados y mandíbula cuadrada, su pelo oscuro y revuelto. Giraba la cabeza en todas direcciones buscando algo, pero sin mirar realmente, como cuando se observa el reloj distraídamente y no se llega a ver la hora. Una mujer caminó hacia él, de pronto ella se dejó caer, y por un segundo pareció que los hermanos se sostenían mutuamente. Camila tenía los ojos grandes y oscuros, como dos pozos profundos, la cara alargada de su hermano, pero sus rasgos eran suaves, femeninos. Él la miró, y bastó eso para que le dijera: está estable, pero en estado crítico. El médico me dijo que tenía una trombosis tardía de la arteria hepática. Se quedó callada. Tomás le sostuvo la mirada y Camila consciente de su real inquietud agregó: sí, necesita otro trasplante...

Hace cinco días que Bárbara estaba hospitalizada en una cama de la UCI, a sus 47 años, producto de una hipertensión endocraneana porque el aneurisma que le habían encontrado hace unos años se había roto. Fue operada suturando la base del aneurisma pero sangró masivamente después. A un lado de su cama estaba Alberto, su marido y al otro, sus hijos María Antonia y Eduardo. La miraban ahí postrada, tan indefensa, viva en el sentido estricto de la palabra, pero realmente sin ninguna posibilidad de volver a "vivir". Habían sido días difíciles: la intervención quirúrgica, la consecuente espera, la expectación y ansiedad, el miedo, el nerviosismo in crescendo, la recuperación que trae consigo el alivio momentáneo y luego la recaída, la espiral que una vez que comienza no acaba hasta alcanzar el fondo. El problema estaba en que ellos no habían llegado a ese final, tal vez una vez abajo tendrían algún alivio, pero por ahora lo único que conocían era esa angustia constante de la incertidumbre que acompaña la caída.

Manuela, la coordinadora de trasplantes estaba teniendo una semana complicada. Hace unos días había reingresado una paciente que necesitaba su tercer trasplante de hígado producto de una trombosis de la arteria hepática y ya estaba calificada como urgencia o prioridad médica en la lista nacional de receptores de órganos. Hasta ahora no había un donante compatible. Conocía a Carolina hace tres años, desde su primer trasplante, y había llegado a conocer y a querer a sus hijos. Ahora ella volvía por una tercera oportunidad. Caminaba por el pasillo hacia la UCI cuando esa mañana le informaron que había una posible donante, faltando aun la confirmación de la muerte encefálica. Como siempre, un sentimiento de preocupación la invadía: es duro ver a un nuevo paciente en esta situación postrado en una cama, con todo el universo que eso implica. Su calidad de coordinadora de trasplante había incrementado en ella esta cualidad, convirtiéndola en una persona con una sensibilidad distinta, no en una mera procuradora de órganos como tal vez su oficio hacía parecer, sino más bien en una “posibilidad de vida”. Estudió el caso de la nueva paciente y ya en su conocimiento confirmó que la mujer en esa cama, Bárbara, era una posible donante. Ahora viene lo difícil pensó, con la emoción que trae esta nueva opción, pero al mismo tiempo con la pena de saber que para salvar una hay que aceptar la pérdida de otra.

Carolina y Bárbara se encontraban en camas enfrentadas, compartiendo cada instante en la misma UCI, ambas en un suspenso de sus vidas.

Ya en la sala de espera, vio a Tomás y Camila, quienes aguardaban en el sillón más alejado, ambos tomándose un café, y mirando de cuando en cuando a Pablo, su hermano menor, quien sentado casi al borde del sillón tenía la mirada perdida. Sonrieron con cortesía y sin mucha emoción. Pensé que nunca más te veríamos -bromeó Tomás-, un poco para quitar la escarcha que la situación dejaba sobre sus cabezas. Manuela se quedó callada un rato y luego les dijo: Tenemos una posible donante y ustedes ya saben como es esto... tendremos que comprobar la compatibilidad y esperar la decisión de los familiares. Esperanzados y sin tener nada más que decir, ambos, Tomás y Camila agradecieron a Manuela.

Bárbara era efectivamente una donante compatible para Carolina. Ahora sólo faltaba el consentimiento de Alberto, junto a sus hijos. Manuela se reunió con ellos una hora más tarde para explicarles los procedimientos para confirmar la muerte encefálica, puesto que es un proceso riguroso que requiere de tiempo y precisión. A continuación les habló de la libertad que tenían para tomar la opción de donar, sin dejar de mencionar la carga emocional que implica y el rol que juega el tiempo en estas decisiones. El esposo y los hijos comprendieron y aceptaron que Bárbara no volvería a la vida. Aun cuando era un escenario probable, no por eso es menos duro. La donación fue algo que les causó dudas, en particular a María Antonia y a Alberto, pues la información que tenían hasta entonces era escasa, y no era un tema que hubieran tocado en familia. Eduardo preguntó quién recibiría los órganos y si existía la posibilidad de que estos salvaran a la enferma trasplantada de 
hígado que estaba en la cama de enfrente de su madre. Había notado la gravedad de su estado, y había visto a los hijos de Carolina. No pudo evitar sentirse identificado con ellos, aun cuando el resultado final fuese el opuesto. La posibilidad de dar vida, a través de una muerte, aunque fuese la de su madre, era una opción que no podía dejar de considerar.

Manuela respondió que efectivamente eso era probable, pero quedó muy preocupada porque en general donante y receptor no tienen contacto, siempre se evita este tipo de situaciones para proteger la intimidad de cada parte, para no enfrentar escenarios tan contrastantes, para respetar el dolor, la libertad de decisión y al mismo tiempo permitir la alegría de la familia del receptor.

\section{Análisis bioético}

El tema de trasplante de órganos, sea de donante vivo o de cadáver, plantea numerosos y diversos aspectos éticos y también legales, algunos de ellos dependientes del tipo de trasplante. Los tópicos más relevantes se relacionan con el concepto y aceptación cultural de la muerte encefálica, con la voluntariedad y gratuidad de la donación de órganos, con los sistemas de procuramiento y finalmente con la asignación de órganos de acuerdo a prioridades establecidas ante su escasez.

El caso de Bárbara con la difícil decisión de su familia, la opción de vida para Carolina con un nuevo trasplante y el delicado trabajo de la coordinadora de trasplantes, lleva a reflexionar en múltiples temas relacionados entre sí. En este análisis sólo se abordan algunos de los aspectos éticos, dejando de lado los aspectos sociales, la escasez de órganos, así como todo lo técnico y detalles legales que escapan al propósito de este artículo.

Lo primero a considerar es tratar de precisar los valores en juego en esta situación. Entre otros, y de alguna manera en conflicto, están el derecho a la vida, salvar una vida y al mismo tiempo encontrarle sentido al final de otra vida, el misterio de la muerte, la generosidad de la donación, el respeto a la voluntad o las creencias de la enferma terminal, y el respeto a los sentimientos y dudas de su familia. La decisión conflictiva es, en este escenario, la aceptación o el rechazo a la solicitud de donación por parte del esposo y de los hijos de Bárbara, en atención a las dificultades emocionales para ellos $\mathrm{y}$ al desconocimiento de su voluntad previa, pero con la perspectiva real de ayudar generosamente a salvar otra vida.

Analizaremos la decisión de donación, algunos aspectos de la realidad social y luego las condiciones de anonimato de la asignación de órganos en casos de trasplante de órganos.
En la decisión de donar los órganos o de aceptar su extracción del cuerpo de un familiar fallecido, entran en juego en primer lugar conceptos acerca de la propiedad y del respeto al cadáver. El cuerpo sin vida no es estrictamente propiedad de nadie pero se reconoce a los familiares el derecho a disponer de él, de acuerdo a las voluntades expresadas con anterioridad por la persona fallecida y a los criterios propios de cada familia. Con la mayor frecuencia el tema no ha sido tratado de manera anticipada y las familias se ven en la situación, como ocurrió en el caso que se comenta, a decidir en tiempo breve y en medio del dolor por la pérdida. De su decisión depende que se retiren de inmediato las medidas de soporte vital como drogas vasoactivas y ventilación mecánica, o que se mantengan por algunas horas hasta la extracción de los órganos si se acepta la donación. Para poder tomar esta decisión resulta necesario que la familia comprenda, sin ninguna duda, que la muerte encefálica se ha establecido mediante pruebas rigurosas aceptadas por normas clínicas y legales, y que por lo tanto la persona ya ha fallecido. Para quienes no comprenden este concepto y piensan que la muerte encefálica es un estado clínico, una etapa previa a la muerte que llegará con la detención de los latidos cardíacos, o que esta muerte podría ser reversible, donar los órganos resulta imposible.

La donación de órganos de cadáver y su aceptación familiar se fundamentan en una ética de la donación que implica generosidad, solidaridad y contribución al bien de una persona desconocida cuya vida se puede salvar, pero junto a estas razones se basa también en el respeto a la autonomía de la persona fallecida. Ella la ha ejercido en vida y es obvio que después de su muerte ya no hay autonomía, pero se mantiene el deber de respeto a sus criterios y valores en relación a la donación. Si no se conoce esta voluntad, la decisión recae exclusivamente en los familiares y aún legalmente se reconoce este derecho, en orden preferente al cónyuge y a los hijos mayores de edad.

En Chile tenemos una tasa de donación muy baja, la que además ha descendido en los últimos años. Entre las razones para el rechazo están precisamente la incomprensión de la muerte encefálica con el temor de que se le acorte la vida al enfermo por el interés de beneficiar a un enfermo más recuperable. Otras razones incluyen el temor a la mutilación del cuerpo o intervenciones que faltarían el debido respeto al cadáver de un ser querido, y se aducen razones religiosas que son más del imaginario social que de disposiciones de las diferentes religiones que más bien favorecen la donación en base a la generosidad y solidaridad. Por último las familias enfrentan la dificultad de representar la voluntad de 
la persona fallecida, especialmente si no ha existido, como en el caso de Bárbara, una expresión escrita ni verbal de su voluntad previa. Desde enero de 2010 está vigente una sustancial modificación de la ley, la cual establece que "las personas cuyo estado de salud lo requiera tendrán derecho a ser receptoras de órganos, y que toda persona mayor de dieciocho años será considerada donante de órganos una vez fallecida, a menos que en vida haya manifestado su voluntad de no serlo”. Esta modalidad de donación presunta, adoptada en diversos países, en la práctica se aplica respetando la voluntad familiar y dando siempre la opción de rechazo a la donación. Sin embargo, contrariamente a la intención de la modificación legal, este nuevo criterio legal no ha significado un aumento en las tasas de donación en el país. La razón está en que más que un cambio legal se requiere comprensión y aceptación de la muerte encefálica, confianza en que el cuidado y tratamiento de los enfermos terminales no depende de que sea o no donante, y una conciencia social solidaria que lleve a aceptar procedimientos que pueden demorar y dificultar las acciones propias de las primeras horas posteriores al fallecimiento.

Otro conjunto de problemas éticos relacionados con los trasplantes de órganos se refiere a su asignación a un enfermo entre muchos que podrían beneficiarse con este tratamiento. Se trata de una ética de la distribución. Es un tema de justicia que se ha resuelto asegurando la independencia entre un equipo médico tratante del donante, los tratantes del potencial receptor, y quienes asignan los órganos. Se busca evitar sesgos o formas de presión y basar la asignación de órganos estableciendo prioridades que incluyen la histocompatibilidad, probabilidad de éxito, patologías asociadas, tiempo en lista de espera, la edad y para algunos órganos la gravedad del enfermo. Sin embargo, estos criterios se postergan en los casos que se califican médicamente como urgencias o prioridad médica, como había ocurrido en el caso de Carolina porque su expectativa de vida en pocos días dependía de recibir un hígado. Si bien estos criterios se respetan de manera estricta, existe el prejuicio social de que en la asignación de órganos pueden influir factores económicos o presiones de diverso tipo. Estos temores, lamentablemente a veces sugeridos por medios de comunicación o por campañas públicas para conseguir órganos para algún enfermo, afectan la confianza ciudadana en el sistema de trasplante de órganos influyendo muy negativamente en las tasas de donación.

Relacionado con lo anterior se ha establecido que la donación de órganos sea gratuita, que no exista ninguna forma de compensación para el donante, pero que todos los gastos relacionados al procuramiento de los órganos corresponden al sistema de salud del receptor. Sin embargo, este criterio, ante la escasez de órganos, ha despertado crecientes voces que lo ponen en discusión. En gran parte por su carácter gratuito, altruista y voluntario se considera que la donación debe ser también anónima, que ni receptores de órganos ni familiares del donante deben conocer la identidad del otro. La ley chilena establece que "no podrán facilitarse ni divulgarse informaciones que permitan identificar al donante".

Sin embargo, el anonimato no es un dogma y en la práctica, a pesar de esta disposición, existen casos en los cuales se llega a conocer quien fue el donante o a quien le fueron trasplantados sus órganos. Son casos en ciudades más pequeñas, casos de receptores que son informados por los medios el mismo día de la intervención o casos como los familiares de Bárbara y de Carolina que se encuentran en una misma institución. Aunque es muy difícil evaluar qué impacto tienen estas pérdidas del anonimato en las personas trasplantadas o en los familiares del donante, hay quienes consideran un beneficio saber que un órgano de un ser querido ha logrado salvar y mantener con vida a tal persona, y también hay casos de trasplantados que buscan vincularse con familiares del donante para expresar su gratitud. En el caso que analizamos es posible pensar que, para el esposo y los hijos de Bárbara, saber que la enferma que habían visto en la misma UCI podría ser la receptora haya influido favorablemente en su decisión de donar. Aceptar los procedimientos de extracción de los órganos es siempre duro para los familiares $\mathrm{y}$ el hecho de imaginar a un receptor puede hacer menos impersonal la decisión.

\section{Referencias}

1. Solar S, Ovalle A, Simian ME, Beca JP. Tres factores que influyen en la actitud de las personas ante la donación de órganos. Rev Chil Cir. 2008;60:262-7. Disponible en http://medicina.udd.cl/centro-bioetica/ publicaciones/

2. Ley 20.413 Modifica la ley $\mathrm{N}^{\circ}$ 19.451, con el fin de determinar quiénes pueden ser considerados donantes de órganos y la forma en que pueden manifestar su voluntad. Disponible en http://www.leychile.cl/Naveg ar?idNorma $=1010132 \&$ buscar $=20413$

3. Página web de la Corporación Chilena del Trasplante: http://www.trasplante.cl

4. Escudero D, Matesanz R, Soratti CA, Flores JI. Consideraciones generales sobre la muerte encefálica y recomendaciones sobre las decisiones clínicas tras su diagnóstico. Med Intensiva 2009;33:450-4. Disponible en http://www.ncbi.nlm.nih.gov/pubmed/19922827

5. Cronin AJ. Authorisation, altruism and compulsión in the organ donation debate. J Med Ethics 2010;36:62731. 